\title{
Metáforas nas Línguas Indígenas
}

Com este volume dedicado ao estudo das línguas e culturas indígenas pelo viés da metáfora, a Revista Brasileira de Linguística Antropológica (RBLA) amplia sua contribuição ao universo dos estudos linguísticos e antropológicos sobre os povos nativos da América do Sul. A escolha da temática foi decorrente dos resultados do Encontro Internacional "Metáforas nas Línguas Indígenas. Abordagem Empírica Linguística e Cognitiva”, realizado pelo Laboratório de Línguas e Literaturas Indígenas, do Instituto de Letras, da Universidade de Brasília, de 24 a 26 de dezembro de 2014. Foram, assim, publicados, no presente volume, os trabalhos apresentados nesse evento, submetidos à RBLA e aceitos para publicação.

Carmen Junqueira abre o volume com o artigo "A linguagem dos ritos", uma aula sobre ritos, em que o Kwaryp é o fio condutor. Junqueira enfatiza que a compreensão dos ritos "requer uma acentuada vigilância a fim de evitar que a lógica do nosso modo de pensar se infiltre na explicitação do significado". Ressalta que a regra principal é "não trabalhar com deduções estranhas ao universo das significações indígenas", como ela o fez em relação ao seu estudo do pensamento Kamaiurá. Em seu artigo, Junqueira focaliza um detalhe do ritual Kwaryp, demonstrando a sua força e importância para o povo Kamaiurá. Trata-se do "discreto gesto da jovem reclusa ao distribuir castanha de pequi aos líderes das aldeias convidadas." Junqueira analisa o seu significado metafórico, buscando na mitologia kamaiurá os elementos que o pudessem explicar. Conclui que a cultura Kamaiurá "Lança mão de um mito para transpor a barreira da interdição", no qual a castanha do pequi é a própria metáfora do amor sensual, "reservando-se para o grande final do Kwaryp o rito da sua distribuição, como uma alegoria à alegria de viver a vida".

Betty Mindlin e Uraan Anderson Suruí, em "Nomes Paiter Suruí: metáfora? Sugestões para a pesquisa pela atual geração de intelectuais Paiter", mostram que os antropônimos Suruí-Paitér têm significados "carregados de poesia: o arco fica nu de flechas de tanto atirar; fala tão bravo que o arco ficará nu de flechas de tanto atirar; nossa casa, casa grande; que faz muitas coisas; carregada de coisas; que faz muito trabalho, [...] roça que fede (depois de queimada)". Ao percorrer os significados dos nomes coletados por Mindlin na época do contato, concluem que todos eles são metáforas. Fazem as seguintes perguntas: "Que conhecimento os Paiter têm hoje das formas de nominação dos anos 80?" 
e "Como as regras brasileiras, que são até mesmo legais, levam ao abandono dos costumes antigos? Quem os mantêm?". Os autores apresentam sugestões de grande importância para ampliar o conhecimento sobre a nomeação entre os Paitér, dentre as quais destacamos a de que os pesquisadores Paitér têm grande responsabilidade nesta investigação, como protagonistas dela. É um trabalho instigante que nos ensina o quanto ainda é preciso se fazer para ampliar o conhecimento científico sobre a riqueza linguístico-cultural indígena, e que nos mostra a importância da documentação antropológica e linguística, como a feita por Mindlin na década de 1980, que deve ser urgentemente retomada e aprofundada, pela importância para os povos indígenas e para o conhecimento científico sobre a sua cultura.

O artigo de Cristina Martins Fargetti "Qual pode ser o alcance de uma metáfora? Através da metáfora" oferece uma interpretação atualizada do significado crucial para o sistema de parentesco Jurúna. Na discussão desenvolvida pela autora, o nome do herói mítico Sela'ã, usado por Lima (1995), na sua explicação do sistema de parentesco Jurúna, compreendendo que os Jurúna "dizem 'nossa batata', no sentido de que se explicam como originários de Sela'ã, a batata de que se esparramaram", é percebido por Lima como metáfora para eles. Entretanto, as pesquisas de Fargetti mostram que "Sela'ã originou-se de uma relação entre uma mulher (cuja origem não conhecemos) e Kumãhari, uma onça". Fargetti explica que ele nunca foi literalmente uma batata, mas é explicado pelos Jurúna, "metaforicamente, como batata, por nunca morrer, por sempre se renovar, como as ramas de batata, a partir de uma original". A autora ressalta que, ao envelhecer, ele sempre trocaria de pele, assim como sua mulher, permanecendo jovens. Para a autora, "A metáfora dos juruna enfatiza, assim, o fato de que Sela'ã diz que eles devem se perpetuar, [...] Assim, como Sela'ã é eterno, o povo juruna também deve ser, embora os juruna não sejam imortais, individualmente". Fargetti reforça, de certa forma, a ideia de Junqueira, neste volume, ao concluir que é preciso também entender as metáforas alheias através dos seus próprios mapeamentos, e não daqueles que pensamos serem interessantes para nossas análises.

Enrique Huelva Unternbäumen, em seu artigo "Metáfora, metonimia y blending en construcciones ditransitivas del kamaiurá", demonstra que o polo semântico das construções ditransitivas dessa língua, analisadas por ele, está formado por "uma rede de integração conceitual que integra as metáforas subjacentes à categoria da TRANSFERENCIA DE OBJETO - constitutiva do significado prototípico de construções ditransitivas - com um conjunto de metáforas e metonímias que têm no corpo humano (ou em partes do mesmo) seu espaço fonte". Conclui que as redes complexas metafórico-metonímicas resultantes dessa integração manifestam particularidades culturais significativas, 
tanto com respeito à sua composição como com respeito às experiências e atividades que ajudam a conceituar. A abordagem das construções ditransitivas Kamaiurá oferecida por Huelva torna conhecidas construções metafóricas dessa língua que ainda não foram, até então, objeto de estudos linguísticos, elucidando aspectos cognitivos subjacentes à sua produtividade na cultura linguística Kamaiurá. Huelva teve como colaboradores Warý Kamaiurá e Paltu Kamaiurá, falantes nativos com formação linguística, o que contou positivamente para a reunião de dados significativos para a fundamentação de sua análise.

O artigo "Metáfora ontológica: a personificação na narrativa mítica e nos processos de formação de palavras Tupí", de Wany Bernardete de Araujo Sampaio e Joeliza Bezerra Lamarão, analisa construções metafóricas ontológicas nas línguas Tupí, com base na teoria cognitiva da metáfora (Lakoff e Johnson 2002), na busca de relações entre a experiência do domínio físico, a natureza conceitual do pensamento e a arquitetura da linguagem. Observam que, no recontar do mito "a origem da lua", por meio de um jogo de sequências de imagens, crianças narradoras fizeram construções metafóricas ontológicas e atribuíram características de humanidade e/ou animacidade a seres como a lua, a noite e as estrelas, o que, segundo as autoras, trata-se da metáfora conceitual - "Corpos celestes são pessoas"-, enquanto a personificação da noite pode ser vista como uma metáfora conceitual do tipo "Tempo é movimento". Características de humanidade em seres celestiais e animais foram identificadas tanto na análise de sentenças complexas, quanto na análise de palavras formadas por composição.

No artigo "Metáforas nos processos de neologia da língua Suruí-Aikewára", Jorge Domingues Lopes, Ikatu Santos Suruí, Tymykong Suruí e Eliete de Jesus Bararuá Solano apresentam uma análise linguística de metáforas nos processos criativos de neologismo pelos Suruí-Aikewára, falantes da língua conhecida também por Suruí-Aikewára (família linguística Tupí-Guaraní, tronco Tupí). São focalizados os modos pelos quais os Suruí constroem significações lexicais/conceptuais para topônimos, animais e coisas, introduzidos em sua cultura, devido ao contato com outras sociedades. O estudo fundamenta-se, principalmente, nos trabalhos de Guilbert (1975), Lakoff \& Jonhson (1980, 2012), Lopes (2014) e nas pesquisas de campo de Cabral, Lopes e Solano $(2012,2013)$. O artigo procura também mostrar "que o processo criativo da metáfora, nas sociedades indígenas, envolve conceitos linguísticos embasados ou 'mergulhados' em um contexto léxico/conceptual interpretativo de uma realidade sociocultural vivenciada em um dado contexto socio-histórico, pela comunidade indígena".

Joeliza Lamarão Bezerra e Wany Bernardete de Araujo Sampaio contribuem também com o artigo "Construções metafóricas espaciais literárias e do 
cotidiano em narrativas míticas indígenas", elegendo como foco da análise expressões que envolvem imagens metafóricas do espaço, a partir do conceito de Metáforas Orientacionais, exemplificadas por expressões como "para cimapara baixo, dentro-fora, frente-trás, em cima de, fora de, fundo-raso, centralperiférico".

A seção Tradução traz o artigo de Chris Sinha e Enrique Bernárdez "Space, Time, and Space-time: metaphors, maps, and fusions", traduzido por Wany Bernardete de Araujo Sampaio. O artigo põe em evidência o fato de que a linguagem do espaço e a linguagem do tempo estão intimamente relacionadas na maioria das línguas, "senão em todas as línguas" e que tem sido proposto que a linguagem do tempo é universalmente derivada da língua do espaço por meio de mapeamentos metafóricos. Os autores contrariam essa hipótese, com base em uma avaliação do espaço e do tempo nas línguas do mundo, mas, reconhecendo que "provavelmente, as motivações cognitivas são universais para tais mapeamentos onde eles ocorrem". Enfatizam também "a variabilidade linguística e cultural das relações linguísticas do espaço-tempo, e observam que os conceitos culturais e linguísticos de tempo podem ser derivados de outros domínios conceituais além do domínio do espaço". Finalmente, reiteram o que é colocado de formas diversas nos demais trabalhos que integram este volume, que a motivação da estrutura linguística pela cognição (incluída pela metáfora conceitual) é sempre mediada por padrões e processos culturais.

Com este volume, a RBLA reafirma o compromisso de seus criadores em contribuir para o conhecimento sobre os povos indígenas da América do Sul, privilegiando a interface de diferentes áreas como mecanismo fundamental para o avanço desse conhecimento. O tema metáfora é aqui explorado por linguistas e antropólogos, em diferentes perspectivas, discutindo dados e metodologias fundamentais para a compreensão da essência das expressões linguísticas dos povos nativos do Brasil, materializada em diversos campos semânticos e discursos de diferentes naturezas.

\author{
Ana Suelly Arruda Câmara Cabral \\ Jorge Domingues Lopes \\ Sanderson Castro Soares de Oliveira \\ Organizadores desta edição
}

